\title{
Prevention and treatment of childhood malnutrition in rural Malawi: Lungwena nutrition studies
}

\section{Chrissie Thakwalakwa ${ }^{1}$, John Phuka ${ }^{1}$, Valerie Flax $^{2}$, Kenneth Maleta ${ }^{1}$, Per Ashorn ${ }^{2}$ \\ 1 College of Medicine, Blantyre, Malawi \\ 2 Tampere University, Finland}

\section{Background of the studies}

Malawi is one of the poorest countries in the world with poor health and nutritional indicators. It is sometimes only surpassed by countries under conflict. Such a situation necessitated a search for local causes of undernutrition which heavily contribute to childhood mortality in Malawi. Literature showed that certain aspects of undernutrition had not been wholly explained. The determination of when growth faltering starts had been hampered by lack of an appropriate reference standard. This raised a question when growth faltering actually start, as preventive strategies had to be instituted early in the development of the problem. For this, local studies were needed. The review highlighted the fact that determinants of malnutrition may not have the same importance in all settings and thus preventive strategies that work in one place may not work in all settings. This meant that determination of local causes and effective interventions was one way of alleviating the problem. It had been standard to consider underweight and stunting as being resultant from the same causal factors. The epidemiology of wasting and stunting and the relationship of weight and height gain suggested possible difference in aetiology and a need to develop a clear understanding of their relationship, which in turn could help in developing effective interventions.

The magnitude of undernutrition in Malawi necessitated a community approach to the management of the problem. The choices for community management were however not well developed. In searching for determinants and preventive strategies, it was also important to develop strategies for managing those children who already suffer from undernutrition. The strategies used for community management of malnutrition in Malawi were largely based on maize/soy supplementation, the effectiveness of which had not been fully established in controlled situations. The fact that the magnitude of the problem had not improved was probably because current methods may not have been effective. This was reason enough to explore new strategies.

\section{Objectives}

To describe typical growth pattern of children, analyse occurrence and determinants of undernutrition and evaluate a community based nutritional intervention for malnourished children in rural Malawi.

The studies are explained in the following papers:

1. Seasonality of growth and the relationship between weight and height gain in children under three years of age in rural Malawi.

\section{Aim}

To describe seasonal pattern of growth and analyse relationship between weight and height gain in children under 3 y of age.

\section{Methods}

A total of 767 children were followed from birth until 36 mo of age in lungwena area, rural Malawi. Weight and height measured at monthly intervals until 18 mo of age and quarterly thereafter. Gains in weight and height and prevalence of malnutrition in different seasons were calculated.

\section{Results}

Weight gain and linear growth velocity showed an agedependent seasonal pattern. After infancy, periods of maximal or minimal height increments systematically occurred 3 mo after those for weight gain. The prevalence of malnutrition also followed a seasonal pattern, peaking a few months after periods of reduced growth. Despite the overall pattern, weight gain and subsequent linear growth were not correlated on an individual level. At any point, however, a child's weight for height was directly, albeit weakly, correlated to height gain in the subsequent 3-mo interval.

\section{Conclusion}

Growth of children under 3 y of age followed an agedependent seasonal pattern. The poor correlation between children's weight and height increments suggests that seasonality affected weight gain and linear growth through different mechanisms.

\section{Timing of growth faltering in rural Malawi}

\section{Aim}

To determine the timing of growth faltering among under 3 year old children.

\section{Methods}

Prospective population based cohort study in Lungwena, rural Malawi, southeast Africa. A total of 767 live born babies were regularly visited from birth until 3 years of age. Weight, height, and mid upper arm circumference were measured at monthly intervals until 18 months and at three month intervals thereafter. Growth charts were constructed using the LMS method and comparisons made to two international databases: the traditional United States National Center for Health Statistics/World Health Organisation (NCHS/ WHO) reference and the 2000 Center for Disease Control (CDC) growth reference.

\section{Results}

Compared to the 2000 CDC reference population, newborns in Lungwena were on average $2.5 \mathrm{~cm}$ shorter and $510 \mathrm{~g}$ lighter. On a population level, height faltering was present at birth and continued throughout the first three years. Weight faltering, on the other hand, occurred mainly between 3 and 12 months of age. At 36 months, the mean weight and height of the study children were $2.3 \mathrm{~kg}$ and $10.5 \mathrm{~cm}$ lower than those of the reference population, respectively. The results remained essentially similar when the comparisons were made to the NCHS/WHO reference.

\section{Conclusions}

The fact that weight and height faltering do not follow identical time patterns suggests that they may have different origin and determinants. Further studies on the aetiology of height faltering and different approaches to preventive interventions are needed. 


\section{Childhood malnutrition and its predictors in rural Malawi}

\section{Objective}

To characterise the timing and predictors of malnutrition Method: A total of 767 rural Malawian children were followed from birth to 36 months.

Results: Underweight and wasting incidence peaked between 6 and 18 months of age, whereas stunting incidence was highest during the first 6 months of age. After infancy about $40 \%$ of the children were underweight, $70 \%$ stunted, and about $4 \%$ wasted. Small size during the first 3 months of life predicted the incidence of severe underweight, severe stunting, and moderate wasting. Children with many illness episodes in infancy had a twofold risk for the development of severe underweight and moderate wasting. Severe underweight was further predicted by residence far away from a health facility and moderate wasting by maternal HIV infection.

\section{Conclusion}

Intrauterine period and first 6 months of life are critical for the development of stunting whereas the subsequent year is more critical for the development of underweight and wasting. Strategies combating intrauterine growth retardation, maternal HIV and infant morbidity are likely to reduce the burden of malnutrition in this population.

\section{Supplementary Feeding of Underweight, Stunted Malawian Children with a Ready-To- Use Food.}

\section{Objective}

To compare the effect of maize and soy flour with that of RTUF in the home treatment of moderately malnourished children.

Methods: Sixty-one underweight, stunted children 42 to 60 months of age were recruited in lungwena area, rural Malawi. They received either RTUF or maize and soy flour for 12 weeks. Both supplements provided $2 \mathrm{MJ}(500 \mathrm{Kcal})$ of energy daily but had different energy and nutrient densities. Outcome variables were weight and height gain and dietary intake.

\section{Results}

Before intervention, the mean dietary intake and weight and height gain were similar in the two groups. During the supplementation phase, the consumption of staple food fell among children receiving maize and soy flour but not among those receiving RTUF. There was thus higher intake of energy, fat, iron, and zinc in the RTUF group. Both supplements resulted in modest weight gain, but the effect lasted longer after RTUF supplementation. Height gain was not affected in either group. Periodic 24-hour dietary recalls suggested that the children received only $30 \%$ and $43 \%$, respectively, of the supplementary RTUF and maize and soy flour provided.

\section{Conclusions}

RTUF is an acceptable alternative to maize and soy flour for dietary supplementation of moderately malnourished children. Approaches aimed at increasing the consumption of supplementary food by the selected recipients are needed.

\section{Growth and change in blood haemoglobin concentration among underweight Malawian infants receiving fortified spreads for 12 weeks: A preliminary trial.}

\section{Objective}

To examine acceptability, growth and change in blood haemoglobin $(\mathrm{Hb})$ concentration among moderately underweight ambulatory infants given fortified spread.

\section{Methods}

A randomised, controlled, parallel-group, investigator-blind clinical trial in rural Malawi. Six- to 17-month-old underweight infants (weight for age $<-2$ ), whose weight was greater than $5.5 \mathrm{~kg}$ and weight-for-height $\mathrm{z}$ score greater than -3 received for 12 weeks at home 1 of 8 food supplementation schemes: nothing, 5, 25, 50, or $75 \mathrm{~g} /$ day milk-based FS or 25,50 , or 75 $\mathrm{g} /$ day soy-based FS. Outcome measures included change in weight, length and blood $\mathrm{Hb}$ concentration.

\section{Results}

A total of 126 infants started and 125 completed the intervention. All infants accepted the spread well, and no intolerance was recorded. Average weight and length gains were higher among infants receiving daily 25 to $75 \mathrm{~g}$ FS than among those receiving only 0 to $5 \mathrm{~g}$ FS. Mean $\mathrm{Hb}$ concentration remained unchanged among unsupplemented controls but increased by 10 to $17 \mathrm{~g} / \mathrm{L}$ among infants receiving any FS. All average gains were largest among infants receiving $50 \mathrm{~g}$ of FS daily: mean difference $(95 \%$ confidence interval) in the 12-week gain between infants in $50 \mathrm{~g}$ milkbased FS group and the unsupplemented group was $290 \mathrm{~g}$ (range, -130 to $700 \mathrm{~g}$ ), $0.9 \mathrm{~cm}$ (range, -0.3 to $2.2 \mathrm{~cm}$ ), and 17 $\mathrm{g} / \mathrm{L}$ (range, 0 to $34 \mathrm{~g} / \mathrm{L}$ ) for weight, length and blood $\mathrm{Hb}$ concentration, respectively. In soy- vs milk-based FS groups, average outcomes were comparable.

\section{Conclusions}

Supplementation with 25 to $75 \mathrm{~g} /$ day of highly fortified spread is feasible and may promote growth and alleviate anaemia among moderately malnourished infants. Further trials should test this hypothesis.

\section{Complementary Feeding With Fortified Spread and Incidence of Severe Stunting in 6- to 18-Month-Old Rural Malawians.}

\section{Objective}

To compare growth and incidence of malnutrition in infants receiving long-term dietary supplementation with ready-touse fortified spread (FS) or micronutrient- fortified maizesoy flour (likuni phala [LP]).

\section{Design}

A randomized, controlled, single-blind trial in rural Malawi. A total of 182 six-month-old infants were randomized to receive 1 year of daily supplementation with $71 \mathrm{~g}$ of LP (282 $\mathrm{kcal}), 50 \mathrm{~g}$ of FS (FS50) (256 kcal), or $25 \mathrm{~g}$ of FS (FS25) (127 kcal).

\section{Outcome Measures}

Weight and length gains and the incidences of severe stunting, underweight, and wasting.

\section{Results}

Mean weight and length gains in the LP, FS50, and FS25 
groups were $2.37,2.47$, and $2.37 \mathrm{~kg}(\mathrm{P}=.66)$ and $12.7,13.5$, and $13.2 \mathrm{~cm}(\mathrm{P}=.23)$, respectively. In the same groups, the cumulative 12 -month incidence of severe stunting was $13.3 \%$, $0.0 \%$, and $3.5 \%(\mathrm{P}=.01)$, of severe underweight was $15.0 \%$, $22.5 \%$, and $16.9 \%(\mathrm{P}=.71)$, and of severe wasting was $1.8 \%$, $1.9 \%$, and $1.8 \%$ (P_.99). Compared with LP-supplemented infants, those given FS50 gained a mean of $100 \mathrm{~g}$ more weight and $0.8 \mathrm{~cm}$ more length. There was a significant interaction between baseline length and intervention $(\mathrm{P}=.04)$; in children with below-median length at enrolment, those given FS50 gained a mean of $1.9 \mathrm{~cm}$ more than individuals receiving LP.

\section{Conclusion}

One-year-long complementary feeding with FS does not have a significantly larger effect than LP on mean weight gain in all infants, but it is likely to boost linear growth in the most disadvantaged individuals and, hence, decrease the incidence of severe stunting.

\section{Post intervention growth of Malawian children who received 12-month dietary 2 complementation with a lipid-based nutrient supplement or maize-soy flour.}

Refer to CAPGAN meeting presentations for the abstract)

\section{Supplementary feeding with fortified spread among moderately underweight $6-18$-month- old rural Malawian children}

\section{Objectives}

To analyse growth and recovery from undernutrition among moderately underweight ambulatory children receiving micronutrient-fortified maize-soy flour (Likuni Phala, LP) or ready-to-use fortified spread (FS) supplementary diet.

One hundred and seventy-six 6-18-month-old individuals were randomized to receive $500 \mathrm{~g} \mathrm{LP}$ or $350 \mathrm{~g}$ FS weekly for 12 weeks.

Baseline and end of intervention measurements were used to calculate anthropometric gains and recovery from underweight, wasting and stunting.

\section{Results}

Mean weight-for-age increased by 0.22 (95\% CI $0.07-0.37)$ and $0.28(0.18-0.40) \mathrm{Z}$-score units in the LP and FS groups respectively. Comparable increase for mean weight-for-length was $0.39(0.20-0.57)$ and $0.52(0.38-0.65)$ Z-score units. Recovery from underweight and wasting was $20 \%$ and $93 \%$ in LP group and $16 \%$ and $75 \%$ in FS group. Few individuals recovered from stunting and mean length-for-age was not markedly changed. There were no statistically significant differences between the outcomes in the two intervention groups.

\section{Conclusion}

In a poor food-security setting, underweight infants and children receiving supplementary feeding for 12 weeks with ready-to-use FS or maize-soy flour porridge show similar recovery from moderate wasting and underweight. Neither intervention, if limited to 12 -week duration, appears to have significant impact on the process of linear growth or stunting. Another study with a no food control group to be done to determine efficacy of maize-soy flour and fortified spread in treating moderate malnutrition.

\section{References}

1.Ashorn P, Maleta K, Espo M, Kulmala T. Male-biased mortality among 1-2 -year old children in rural Malawi. Arch Dis Child 2002;87:386387.

2.Espo M. Infant mortality and its underlying determinants in rural Malawi. Academic dissertation. Acta Universitatis Tamperensis 870, Juvenes Print, Tampere, 2002.

3.Espo M, Kulmala T, Maleta K, Cullinan T, Salin ML, Ashorn P. Determinants of linear growth and predictors of severe stunting during infancy in rural Malawi. Acta Paediatr. 2002;91(12):1364-70.

4.Flax V, Ashorn U, Phuka J, Maleta K, Manary MJ, Ashorn P. Feeding patterns of moderately underweight children in rural Malawi given supplementary fortified spread at home. Maternal and Child Nutrition, 2008;4:65-73.

5.Galpin L, Thakwalakwa C, Phuka J, Ashorn P, Maleta K, Wong WW, Manary MJ. Breast milk intake is not reduced more by the introduction of energy dense complementary food than by typical infant porridge. $\mathrm{J}$ Nutr, 2007;137:1828-183

6.Kulmala T, Vaahtera M, Ndekha M, Cullinan T, Salin M-L Koivisto A-M, Ashorn P. Socio-economic support for good health in rural Malawi. East Afr Med J 2000;77:168-171.

7.Kulmala T, Vaahtera M, Ndekha M, Cullinan T, Salin M-L Koivisto A-M, Ashorn P. The importance of preterm births for peri-and neonatal mortality in rural Malawi. Paediatr Perinat Epidemiol 2000:14;219-26 8.Kulmala T, Vaahtera M, Rannikko J, Ndekha M, Cullinan T, Salin M-L, Ashorn P. The relationship between antenatal risk characteristics, place of delivery and adverse delivery outcome in rural Malawi. Acta Obstet Gynecol Scand 2000;79:984-990

9.Kulmala T. Maternal health and pregnancy outcomes in rural Malawi. Academic dissertation. Acta Universitatis Tamperensis 785, Juvenes Print, Tampere, 2000.

10.Kulmala T, Vaahtera M, Ndekha M, Cullinan T, Salin M-L Koivisto A-M, Ashorn P. Gestational health and predictors of newborn weight amongst pregnant women in rural Malawi. Afr $\mathrm{J}$ Reprod Health 2001;5:99-108.

11.Kuusipalo H, Maleta K, Briend A, Manary MJ, Ashorn P. Growth and change in blood haemoglobin concentration among underweight Malawian infants receiving supplementation with fortified spreads for 12 weeks. J Pediatr Gastroenterol Nutr, 2006; 43:525-532.

12.Maleta K, Virtanen S, Espo M, Kulmala T, Ashorn P. Timing of growth faltering in rural Malawi. Arch Dis Child, 2003;88:574-578.

13.Maleta K, Virtanen S, Espo M, Kulmala T, Ashorn P. Seasonality and the relationship between weight and height gain in rural Malawi. Acta Paediatrica, 2003;92:491-497.

14. Maleta K. Growth and undernutrition in rural Malawian children. Academic dissertation. Acta Universitatis Tamperensis 934, Juvenes Print, Tampere, 2003.

15.Maleta K, Virtanen S, Espo M, Kulmala T, Ashorn P. Childhood malnutrition and its predictors in rural Malawi. Paediatr Perinat Epidemiol. 2003 Oct;17(4):384-90.

16. Maleta K, Kuittinen J, Duggan MB, Briend A, Manary MJ, Wales J, Kulmala T, Ashorn P. Supplementary feeding of underweight, stunted Malawian children with a ready-to-use food. J Pediatr Gastroenterol Nutr, 2004;38:152-158.

17.Ndekha M, Kulmala T, Vaahtera M, Cullinan T, Salin M-L, Ashorn P. Seasonal variation in the dietary sources of energy for pregnant women in Lungwena rural Malawi. Ecol Food and Nutr 2000;38:605-622

18.Phuka J C, Maleta K, Thakwalakwa C, Cheung YB, Briend A, Manary MJ, Ashorn P. Complementary feeding with fortified spread 
and incidence of severe stunting among 6-18 month old rural Malawian infants. Arch Pediatr Adolesc Med. 2008;162(7):619-626.

19.Phuka JC, Maleta K, Thakwalakwa C, Cheung YB, Briend A, Manary MJ Ashorn P . Post-intervention growth of Malawian children who received 12 month dietary complementation with a Lipid-based Nutrient Supplement or Maize-Soy Flour. Am J Clin Nutr 2009;89382:90

20.Phuka J, Thakwalakwa C, Maleta K, Cheung YB, Briend A, Manary MJ Ashorn P. Supplementary feeding with fortified spread among moderately underweight 6-18-month-old rural Malawian children. Matern Child Nutr. 2009 Apr;5(2):159-70

21.Vaahtera M, Kulmala T, Ndekha MD, Koivisto A-M, Cullinan T, Salin M-L, Ashorn P. Antenatal and perinatal predictors of infant mortality in rural Malawi. Arch Dis Child Fetal Neonatol Ed 2000;82:F200-F204

22.Vaahtera M, Kulmala T, Maleta K, Cullinan T, Salin M-L, Ashorn P. Morbidity and health seeking behaviour in a cohort of 702 infants in rural Malawi. Pediatr Perinat Epid 2000;14:225-229

23.Vaahtera M, Kulmala T, Hietanen A, Ndekha M, Cullinan T, Salin M-L, Ashorn P. Breast-feeding and supplementary feeding practices in rural Malawi. Acta Paediatr 2001;90:328-332. 